\title{
Correction to: Aetiology, diagnosis, and treatment of brachymetatarsia: a narrative review
}

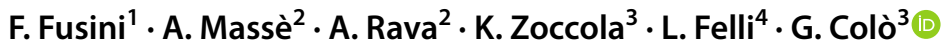

Published online: 2 August 2021

(C) Istituto Ortopedico Rizzoli 2021

\section{Correction to: Musculoskeletal Surgery https://doi.org/10.1007/s12306-021-00720-z}

The original version of this article unfortunately contained a mistake. Given name and family name of Massè A, Zoccola $\mathrm{K}$. were interchanged.

The correct given name and family name should be:

Given name: A.

Family name: Massè

Given name: K.

Family name: Zoccola

Publisher's Note Springer Nature remains neutral with regard to jurisdictional claims in published maps and institutional affiliations.

The original article can be found online at https://doi.org/10.1007/ s12306-021-00720-z.

G. Colò

gabriele.colo@yahoo.it

1 Department of Orthopaedics and Traumatology, Regina Montis Regalis Hospital, ASL CN1, Via S. Rocchetto, 99, 12084 Mondovì, CN, Italy

2 Department of Orthopaedics and Traumatology, Orthopaedic and Trauma Centre, Città della Salute e della Scienza di Torino, University of Turin, Via Zuretti 29, 10121 Turin, Italy

3 Department of Orthopaedics and Traumatology, Regional Center for Joint Arthroplasty, ASO Alessandria, Via Venezia 16, 16121 Alessandria, Italy

4 Orthopaedic Clinic, Department of Surgical Sciences (DISC), University of Genoa, Ospedale Policlinico San Martino, Largo Rosanna Benzi 10, 16132 Genoa, Italy 